\title{
Lithium Diffusivity of Tin-based Film Model Electrodes for Lithium-ion Batteries
}

\author{
Sukhyun Hong ${ }^{1, \dagger}$, Hyuntak Jo ${ }^{1, \dagger}$, and Seung-Wan Song ${ }^{1,2 *}$ \\ ${ }^{1}$ Department of Energy Science and Technology, \\ ${ }^{2}$ Department of Chemical Engineering \& Applied Chemistry, Chungnam National University, Daejeon 305-764, Republic \\ of Korea
}

\begin{abstract}
Lithium diffusivity of fluorine-free and -doped tin-nickel (Sn-Ni) film model electrodes with improved interfacial (solid electrolyte interphase (SEI)) stability has been determined, utilizing variable rate cyclic voltammetry (CV). The method for interfacial stabilization comprises fluorine-doping on the electrode together with the use of electrolyte including fluorinated ethylene carbonate (FEC) solvent and trimethyl phosphite additive. It is found that lithium diffusivity of Sn is largely dependent on the fluorine-doping on the Sn-Ni electrode and interfacial stability. Lithium diffusivity of fluorinedoped electrode is one order higher than that of fluorine-free electrode, which is ascribed to the enhanced electrical conductivity and interfacial stabilization effect.
\end{abstract}

Keywords : Lithium-ion batteries, Lithium diffusivity, Tin-nickel anode, Film model electrode, Fluorine-doping, Interfacial stability

Received July 13, 2015 : Accepted November 2, 2015

\section{Introduction}

Tin (Sn)-based materials have been recognized as one of the attractive anode materials, which can replace the commercialized graphite, primarily because of the larger theoretical capacity $\left(\sim 994 \mathrm{mAhg}^{-1}\right)$ of $\mathrm{Sn}$ than that of graphite $\left(\sim 372 \mathrm{mAhg}^{-1}\right)$ [1]. In addition, the $\mathrm{Sn}$ appeal its merits of appropriate operating voltage above lithium (Li) that prevents dendrite formation, high electric conductivity as metallic, ductile property that is convenient for a handy fabrication of the batteries in diverse architectures [2], and a different reaction mechanism, which is based on Li-Sn alloy formation [1], from $\mathrm{Li}^{+}$-intercalation mechanism of graphite.
Improved battery safety and rate capability are then expected. Sn-based anode materials, however, suffer from a rapid performance fade due to a large volume change followed by particle cracking event during lithiation/delithiation and the loss of electrical contact between individual particles and between particles and current collector [1]. It has been established that interfacial instability of Sn electrode with electrolyte is due to the attack of $\mathrm{LiPF}_{6}$-derived acidic species $\left(\mathrm{PF}_{5}, \mathrm{PF}_{3} \mathrm{O}\right.$, $\mathrm{HF})$ and this additionally deteriorates the electrical disintegration [3-5]. Interfacial stabilization and the formation of stable solid electrolyte interphase (SEI) have been suggested as one of the most effective approaches for enhancing the cycling performance of Sn-based

\footnotetext{
These authors contributed equally.

*Corresponding author. Tel.: +82-42-821-7008

E-mail address: swsong@cnu.ac.kr
}

\section{Open Access DOI: http://dx.doi.org/10.5229/JECST.2015.6.4.116}

This is an Open Access article distributed under the terms of the Creative Commons Attribution Non-Commercial License (http:/creativ ecommons.org/licenses/by-nc/3.0/) which permits unrestricted non-commercial use, distribution, and reproduction in any medium, provided the original work is properly cited. 
anodes. Our earlier work showed that the use of trimethyl phosphite $\left(\mathrm{P}\left(\mathrm{OCH}_{3}\right)_{3}\right.$, TMP) as a Lewis base electrolyte additive, which captures the $\mathrm{LiPF}_{6}$-derived Lewis acids $\left(\mathrm{PF}_{5}\right.$ and $\left.\mathrm{PF}_{3} \mathrm{O}\right)$, and fluorine $(\mathrm{F})$-doping on $\mathrm{Sn}$, which produces positively charged $\mathrm{Sn}$ and induces to capture $\mathrm{F}^{-}$ions from $\mathrm{HF}$ that is always present in $\mathrm{LiPF}_{6}$-contaiing carbonate-based electrolyte, were effective in enhancing the interfacial and SEI stability and cycling performance $[5,6]$.

Lithium diffusivity is an intrinsic property of $\mathrm{Li}^{+}$ ion-conducting electrode material. It is generally proposed that the rate of lithiation process of electrode is controlled by lithium diffusivity [7]. Determination of lithium diffusivity and understanding of lithium diffusion behavior are crucial in controlling the charge-discharge cycling behavior and performance, and rate capability. Various methods have been used to determine the lithium diffusivity of $\mathrm{Sn}$ and silicon (Si) alloy anodes, such as galvanostatic intermittent titration technique (GITT) [8], potentiostatic intermittent titration technique (PITT) [9], electrochemical impedance spectroscopy (EIS) $[10,11]$ and cyclic voltammetry (CV) [11-14]. However, the reported diffusivities of $\mathrm{Sn}$ are not consistent with each other being in the range of $10^{-8}-10^{-7} \mathrm{~cm}^{2} \mathrm{~s}^{-1}[1,8]$, since the measurements were conducted under the condition of no control of interfacial stability to electrolyte. Then, electrolyte continued to be electrochemically reduced and decomposed with cycling, consuming an extra charge and resulting in irreversible electrochemical signals. In addition, since conductive material (e.g., graphite) was necessary for the bulk Sn-based anodes to accommodate the volume change $[15,16]$, lithium diffusivity of Sn alone was not able to be measured.

Studies of dense film model electrode can give a clearer insight into the intrinsic properties of electrode material without complications from carbon and polymeric binder additives that are necessary in bulk electrodes for enhanced electric conductivity and particle connection [3-5,17-23]. Film electrode homogeneously deposited on a conductive substrate can have a robust structure and strong adherence to the substrate, yielding a good model system for the study of lithium diffusion kinetics during electrochemical charge and discharge cycling. Our earlier work showed that interfacial stabilization of pulsed laser deposited (PLD) Si film model electrodes on $\mathrm{Cu}$ substrate by constructing the surface protective siloxane network at the electrode surface using silane additive provides the lithium diffusivity in the order of $10^{-13} \mathrm{~cm}^{2} \mathrm{~s}^{-1}[19,22]$. There is no prior record of lithium diffusivity study for Sn-based film model electrodes prepared by PLD.

Here, we report the determination of lithium diffusivity of F-free and F-doped Sn-Ni PLD film model electrodes under the condition of interfacial stabilization, utilizing variable rate $\mathrm{CV}$. The influences of Fdoping on the lithium diffusivity and electrolyte composition are discussed.

\section{Experimental}

The 500 - $550 \mathrm{~nm}$ thick film model electrodes of fluorine (F)-free and F-doped Sn-Ni were deposited on stainless steel substrates by PLD at $40^{\circ} \mathrm{C}$ in 0.9 mtorr of Ar back pressure, using a $\mathrm{KrF}$ excimer laser with an energy density of $\sim 3-4 \mathrm{mJcm}^{-2}$ at $10 \mathrm{~Hz}$ impinging on the targets which consisted of $\mathrm{Sn}$ and $\mathrm{Ni}(65: 35$ in mol\%) or $\mathrm{Sn}, \mathrm{Ni}$ and $\mathrm{SnF}_{2}(64.35: 34.65: 1$ in $\mathrm{mol} \%$ ), respectively. Targets were prepared by ball-milling of $\mathrm{Sn}$ and $\mathrm{Ni}$ (and $\mathrm{SnF}_{2}$ ) powders and then pressing at $200 \mathrm{kgcm}^{-2}$. The crystal structure, relative atomic ration of $\mathrm{Sn}$ to $\mathrm{Ni}$, the thickness and surface morphology of as-deposited films were determined and confirmed as described in our earlier works [5].

Proto-type three-electrodes lithium cells were assembled with the as-deposited F-free or F-doped Sn$\mathrm{Ni}$ film electrode as a working electrode, lithium metal foils as a reference and a counter electrodes, and the electrolytes of $1 \mathrm{M} \mathrm{LiPF}_{6} /$ ethylene carbonate (EC):ethyl methyl carbonate (EMC) (30:70 volume\% ratio, Panax E-Tec, $\mathrm{H}_{2} \mathrm{O}$ content $<10 \mathrm{ppm}$ ) and $1 \mathrm{M}$ $\mathrm{LiPF}_{6} /$ fluoroethylene carbonate (FEC):diethyl carbonate (DEC) (50:50 volume\% ratio, Panax E-Tec, $\mathrm{H}_{2} \mathrm{O}$ content $<10 \mathrm{ppm}$ ) with $3 \mathrm{wt} \%$ trimethyl phosphite $\left(\mathrm{P}\left(\mathrm{OCH}_{3}\right)_{3}\right.$, TMP, $99 \%$, Aldrich $)$ as an additive. Lithium cell assembly and electrochemical measurement were made in Ar-filled glove box at room temperature.

Variable rate $\mathrm{CV}$ was carried out at a sweep rate from 100 to $0.1 \mathrm{mVs}^{-1}$ between 0.05 and $1.5 \mathrm{Vvs}$. Li/ $\mathrm{Li}^{+}$, using a potentiostat (VSP SP-150, Bio-Logic). The lithium diffusivity was calculated from the plot of peak current $\left(I_{p}\right) v s$. the square-root of sweep rate $\left(\mathrm{n}^{1 / 2}\right)$ using the least square method.

\section{Results and Discussion}

Fig. 1a-b show the CVs of the F-free Sn-Ni film 

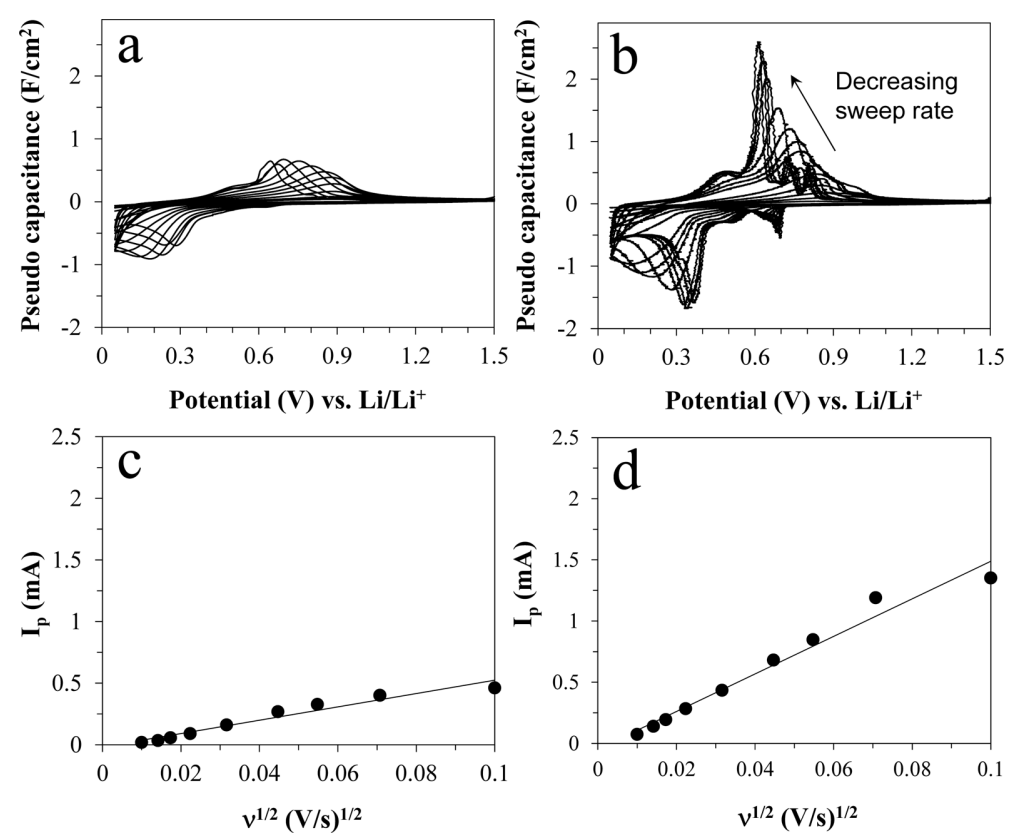

Fig. 1. Cyclic voltammograms of the lithium cells with F-free Sn-Ni film electrodes in the electrolytes of (a) $1 \mathrm{M} \mathrm{LiPF}_{6} /$ EC:EMC with $3 \mathrm{wt} \% \mathrm{TMP}$ additive and (b) $1 \mathrm{M} \mathrm{LiPF}_{6} / \mathrm{FEC}: \mathrm{DEC}$ with $3 \mathrm{wt} \% \mathrm{TMP}$ at a variable sweep rate (n) from 100 to $0.1 \mathrm{mVs}^{-1}$, and $(\mathrm{c}-\mathrm{d})$ the dependence of peak current $\left(I_{P}\right)$ on the square-root of sweep rate $\left(v^{1 / 2}\right)$.

electrodes in $1 \mathrm{M} \mathrm{LiPF}_{6} / \mathrm{EC}: \mathrm{EMC}$ and $1 \mathrm{M} \mathrm{LiPF}_{6} /$ FEC:DEC, respectively, with $3 \mathrm{wt} \%$ TMP additive. The $y$ axes are expressed as pseudo capacitances $(I / v)$ by normalizing the current $I$ with the sweep rate n that varied from 100 to $0.1 \mathrm{mV} / \mathrm{s}$. While the peak currents of both cathodic and anodic processes in the EC-based electrolyte (Fig. 1a) are broad and small in all sweep rates, those in the FEC-based electrolyte (Fig. 1b) are at a much higher peak resolution. This indicates that FEC is effective in improving the interfacial stability and consequently providing the increased electrochemical charge-discharge capacity and cycling reversibility of Sn. As decreasing the sweep rate (Fig. 1b), the pseudo capacitance of both cathodic and anodic peaks increases and peaks becomes sharper, then, they are separated into individual peaks. Thus, in Fig. 1b, the peak currents at the slowest sweep rate of $0.1 \mathrm{mVs}^{-1}$ enable to be assigned; the cathodic peaks at $0.7,0.53$ and $0.37 \mathrm{~V}$, due to lithiation process of Sn, correspond to the formation of $\mathrm{Li}_{0.4} \mathrm{Sn}_{2} \mathrm{Li}_{2.33} \mathrm{Sn}$ and $\mathrm{Li}_{4.4} \mathrm{Sn}$, respectively $[1,24]$. The anodic peaks near $0.5,0.61,0.71$ and $0.8 \mathrm{~V}$, by delithiation from $\mathrm{Li}_{4.4} \mathrm{Sn}$, are due to subsequent regeneration of $\mathrm{Li}_{3.5} \mathrm{Sn}_{2} \mathrm{Li}_{2.33} \mathrm{Sn}, \mathrm{LiSn}$ and $\mathrm{Sn}$, respectively [1,24]. In this study, we take the anodic peak at $0.61 \mathrm{~V}$, which corresponds to the removal of

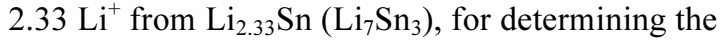
lithium diffusivity, as it is observed in common regardless of sweep rate.

Fig. 1c-d reveal that the anodic peak current $\left(I_{p}\right)$ at $0.61 \mathrm{~V}$ is linearly proportional to the square-root of sweep rate $\left(v^{1 / 2}\right)$ in the sweep rate region of 0.1 $10 \mathrm{mVs}^{-1}$, rather than to the sweep rate $(v)$. This is characteristic of semi-infinite lithium diffusion process [25], which may include the lithium diffusion to the SEI layer to Sn electrode. The slope of $I_{p} v s . v^{1 / 2}$ was used for the determination of lithium diffusivity using Randles-Sevcik equation. ${ }^{25}$

$$
I_{p}=\left(2.69 \times 10^{5}\right) \times n^{3 / 2} \mathrm{~A} D_{L i}^{1 / 2} C_{L i}^{*}{ }^{+}+v^{1 / 2}
$$

The determined diffusivities are $1.01 \times 10^{-7} \mathrm{~cm}^{2} \mathrm{~s}^{-1}$ in the EC-based electrolyte and $8.12 \times 10^{-7} \mathrm{~cm}^{2} \mathrm{~s}^{-1}$ in the FEC-based electrolyte respectively, as listed in Table 1. The use of FEC-based electrolyte for F-free electrode results in an increase in the lithium diffusivity, which is ascribed to its effectiveness of interfacial stabilization.

Fig. 2a-b exhibit the variable rate CVs of F-doped $\mathrm{Sn}-\mathrm{Ni}$ electrode in $1 \mathrm{M} \mathrm{LiPF}_{6} / \mathrm{EC}: \mathrm{EMC}$ and $1 \mathrm{M}$ 
Table 1. Lithium diffusivity of F-free and F-doped Sn-Ni film electrodes in $1 \mathrm{M} \mathrm{LiPF}_{6} / \mathrm{EC}$ :EMC (EC-based) and $1 \mathrm{M} \mathrm{LiPF}_{6} /$ FEC:DEC (FEC-based) electrolytes (EL) with 3wt\% TMP additive.

\begin{tabular}{ccccc}
\hline & $\begin{array}{c}\text { F-free electrode, } \\
\text { EC-based EL }\end{array}$ & $\begin{array}{c}\text { F-free electrode, } \\
\text { FEC-based EL }\end{array}$ & $\begin{array}{c}\text { F-doped electrode, } \\
\text { EC-based EL }\end{array}$ & $\begin{array}{c}\text { F-doped electrode, } \\
\text { FEC-based EL }\end{array}$ \\
\hline $\begin{array}{c}\text { Lithium } \\
\text { diffusivity }\left(\mathrm{cm}^{2} \mathrm{~s}^{-1}\right)\end{array}$ & $1.01 \times 10^{-7}$ & $8.12 \times 10^{-7}$ & $2.21 \times 10^{-6}$ & $1.22 \times 10^{-6}$ \\
\hline
\end{tabular}
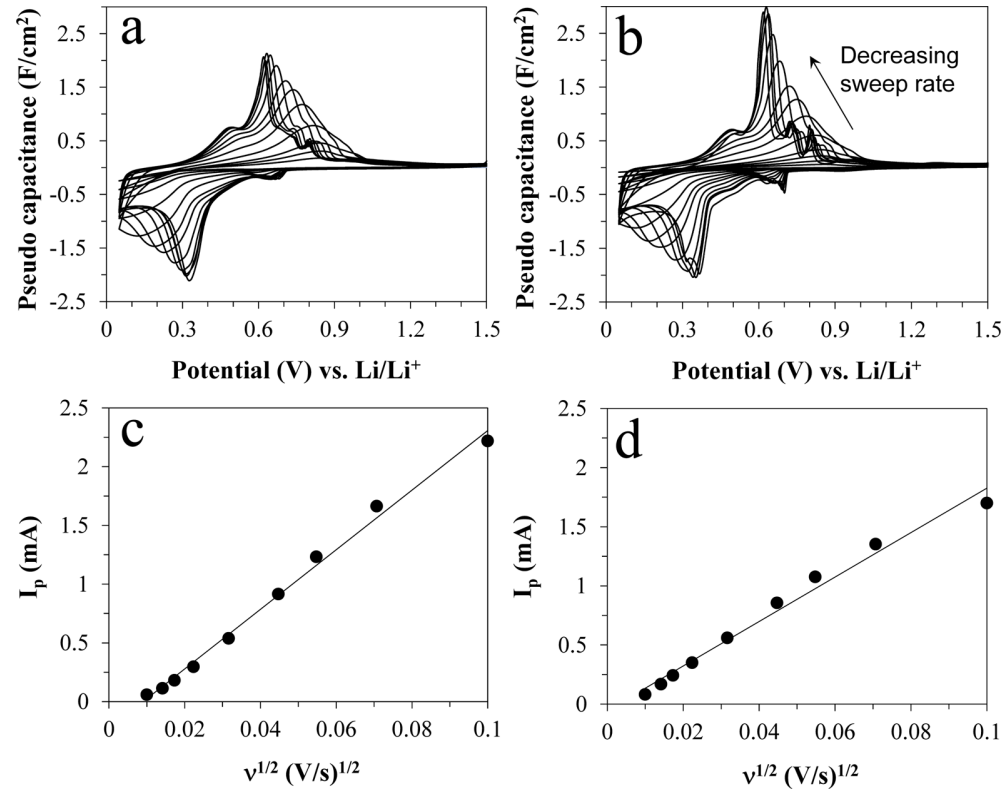

Fig. 2. Cyclic voltammograms of the lithium cells with F-doped Sn-Ni film electrodes in the electrolytes of (a) $1 \mathrm{M} \mathrm{LiPF}_{6} /$ EC:EMC with $3 \mathrm{wt} \% \mathrm{TMP}$ and (b) $1 \mathrm{M} \mathrm{LiPF}_{6} / \mathrm{FEC}: \mathrm{DEC}$ with $3 \mathrm{wt} \% \mathrm{TMP}$ at a variable sweep rate (n) from 100 to $0.1 \mathrm{mVs}^{-1}$, and (c-d) the dependence of peak current $\left(I_{P}\right)$ on the square-root of sweep rate $\left(v^{1 / 2}\right)$.

$\mathrm{LiPF}_{6} / \mathrm{FEC}: \mathrm{DEC}$, respectively, with $3 \mathrm{wt} \% \mathrm{TMP}$ additive. Compared to the broad CVs of F-free electrodes (Fig. 1a-b), peaks resolution in the CVs of Fdoped electrode (Fig. 2a-b) is significantly improved and a higher pseudo capacitance of cathodic and anodic peak are obtained. Fig. $2 \mathrm{c}-\mathrm{d}$ show the plots of the anodic peak current $\left(I_{p}\right)$ at $0.61 \mathrm{~V} v s$. the squareroot of sweep rate $\left(v^{1 / 2}\right)$ in the sweep rate region of $0.1-10 \mathrm{mVs}^{-1}$. The determined lithium diffusivities of F-doped Sn-Ni electrodes are $2.21 \times 10^{6} \mathrm{~cm}^{2} \mathrm{~s}^{-1}$ in the EC-based electrolyte and $1.22 \times 10^{6} \mathrm{~cm}^{2} \mathrm{~s}^{-1}$, as listed in Table 1. These are one order higher than those of F-free electrodes. Recollect that the surface of both F-free and -doped Sn-Ni film electrodes possess a plenty of surface tin oxide, and the surface of $\mathrm{F}$-doped electrode includes $\mathrm{SnF}_{2}$ and $\mathrm{O}-\mathrm{Sn}-\mathrm{F}$ bond, as described in the earlier work $[5,26]$. This implies that F-doping occurs on not only $\mathrm{Sn}$ but also $\mathrm{SnO}_{2}$ forming $\mathrm{SnO}_{2 \mathrm{y}} \mathrm{F}_{\mathrm{y}}$ type material, which contributes to an increase in the electrical conductivity $[5,26]$. In general, lithium diffusivity is dependent on the electrical conductivity of electrode materials. Also recollect that the important role of $\mathrm{F}$-doping on $\mathrm{Sn}$ is to capture $\mathrm{F}^{-}$ions from HF present in the $\mathrm{LiPF}_{6}$-containing carbonate-based electrolyte while producing a surface protective SEI layer and providing a better preservation of electrode structure and composition [5]. It is thus determined that the higher lithium diffusivity of F-doped Sn-Ni electrodes than that of F-free electrodes is believed to be due to enhanced electrical conductivity and interfacial stability to electrolyte.

\section{Conclusions}

Lithium diffusivity of F-free and F-doped Sn-Ni film model electrodes in the EC-based and FECbased electrolytes with trimethyl phosphite additive has been determined using cyclic voltammetry. 
While the lithium diffusivity of F-free Sn-Ni electrodes is in the order of $10^{-7} \mathrm{~cm}^{2} \mathrm{~s}^{-1}$, it increases to one order higher level of $10^{-6} \mathrm{~cm}^{2} \mathrm{~s}^{-1}$ upon F-doping. The F-doping on the Sn-Ni film electrode is believed to promote lithium diffusivity by the enhancement of electrical conductivity and interfacial stability to electrolyte.

\section{Acknowledgements}

This work was supported by the Korean Ministry of Science, ICT \& Future Planning (2013K000214), and Ministry of Education and National Research Foundation (2012026203).

\section{References}

[1] M. Winter and J. O. Besenhard, Electrochim. Acta, 45, 31 (1999).

[2] Y. H. Kwon, S.-W. Woo, H.-R. Jung, H. K. Yu, K. Kim, B. H. Oh, S. Ahn, S.-Y. Lee, S.-W. Song, J. Cho, H.-C. Shin, and J. Y. Kim, Adv. Mater., 24, 5192 (2012).

[3] S.-W. Song and S.-W. Baek, Electrochim. Acta, 54, $1312(2009)$

[4] S.-W. Baek, S.-J. Hong, D.-W. Kim, and S.-W. Song, J. Power Sources, 189, 660 (2009).

[5] M.-H. Choo, C. C. Nguyen, S. Hong, Y. H. Kwon, S.W. Woo, J. Y. Kim, and S.-W. Song, Electrochim. Acta, 112, 252 (2013).

[6] S. Hong, M.-H. Choo, Y. H. Kwon, J. Y. Kim, and S.W. Song, J. Electrochem. Soc., 161, A1851 (2014).

[7] M. Park, X. Zhang, M. Chung, G. B. Less, and A. M. Sastry, J. Power Sources, 195. 7904 (2010).

[8] J. Wang, I. D. Raistrick, and R. A. Huggins, J. Electrochem. Soc., 133, 457 (1986).

[9] J. Xie, N. Imanishi, T. Zhang, A. Hirano, and Y. Takeda, and O. Yamamoto, Mater. Chem. Phys., 120, 421 (2010).
[10] A. V. Churikov, K. I. Pridatko, A. V. Ivanishchev, I. A. Ivanishcheva, I. M. Gamayunova, K. V. Zapsis, and V. O. Sycheva, Russian J. Electrochem., 44, 550 (2008)

[11] T. Zhang, H. P. Zhang, L. C. Yang, B. Wang, Y. P. Wu, and T. Takamura, Electrochim. Acta., 53, 5660 (2008).

[12] S. H. Nguyen, J. C. Lim, and J. K. Lee, Electrochim. Acta, 74, 53 (2012).

[13] H. Li, F. Cheng, Z. Zhu, H. Bai, Z. Tao, and J. Chen, J. Alloys \& Compds., 509, 2919 (2011).

[14] K. Tasaki, A. Goldberg, J.-J. Lian, M. Walker, A. Timmons, and S. J. Harris, J. Electrochem. Soc., 156, A1019 (2009).

[15] W.-M. Zhang, J.-S. Hu, Y.-G. Guo, S.-F. Zheng, L.-S. Zhong, W.-G. Song, and L.-J. Wan, Adv. Mater, 20, 1160 (2008).

[16] C.-J. Liu, H. Hang, G.-Z. Cao, F.-H. Xue, R. A. P. Camacho, and X.-L. Dong, Electrochim. Acta, 144, 376 (2014).

[17] S.-W. Song, R. P. Reade, R. Kostecki, and K. A. Striebel, J. Electrochem. Soc., 153, A12 (2006)

[18] S.-W. Song and S.-W. Baek, Electrochem. Solid-State Lett, 12, A23 (2009).

[19] C. C. Nguyen and S.-W. Song, Electrochim. Acta, 55, 3026 (2010).

[20] C. C. Nguyen, D.-W. Kim, and S.-W. Song, $J$. Electrochem. Sci. \& Tech., 2, 8 (2011).

[21] C. C. Nguyen, S.-W. Woo, and S.-W. Song, J. Phys. Chem. C, 116, 14764 (2012).

[22] C. C. Nguyen and S.-W. Song, J. Electrochem. Sci. \& Tech, 4, 108 (2013).

[23] C. C. Nguyen, H. Choi, and S.-W. Song, J. Electrochem. Soc., 160, A906 (2013).

[24] I. A. Courtney, J. S. Tse, O Mao, J. Hafner, and J. R. Dahn, Phys. Rev. B, 58, 583 (1998).

[25] A. J. Bard and L. R. Faulkner, Electrochemical Methods: Fundamentals and Applications, 2nd ed., John Wiley \& Sons, Inc., New York (2001).

[26] R. Mientus and K. Ellmer, Surf. Coat. Technol., 98, 1267 (1998). 